\title{
Night Sky Protection Initiatives in Argentina
}

\author{
Beatriz García ${ }^{1}$, Silvina Pérez Álvarez ${ }^{1}$, Victor Bibé ${ }^{2}$, Andrés Risi ${ }^{3}$ \\ and Lisandro Gino ${ }^{4}$ \\ ${ }^{1}$ ITeDAM, CNEA,CONICET, UNSAM, Mendoza, Argentina \\ email: beatriz.garcia@iteda.cnea.gov.ar \\ ${ }^{2}$ Asociación Sigma Octantis, Ushuaia, Tierra del Fuego, Argentina \\ ${ }^{3}$ Planetario Malargüe, Mendoza, Argentina \\ ${ }^{4}$ UCSE, Rafaela, Santa Fe, Argentina
}

\begin{abstract}
Light Pollution is a global problem. Some local actions carried out by a network of professional and amateur astronomers in Argentina are changing the way to attack this problem, taking into account measurements, education, public activities, planetarium shows and legislation proposals.
\end{abstract}

Keywords. Light Pollution control, Light Pollution: Education and Outreach, Light Pollution: Normatives

\section{Introdution}

Light pollution is one of the subjects of our time. The growing population of our planet has little awareness of this kind of problem, which in addition with other forms of contamination, will impact the quality of life. Malargüe, in Mendoza; Rafaela, in Santa Fe; and Ushuaia, in Tierra del Fuego; can be the corners of a work to modify habits about light use, showing that is possible avoid light pollution, and proving that a few people can be a factor of change to transform the behavior of the community where they live.

\section{Objectives and Main Goals}

The initiatives have as main objectives:

- Demonstrate that the light pollution modify our life and the life of the whole ecosystems.

- Show that we can control light pollution to recover the night landscape.

- Propose and implement local legislation which can be transformed to a National Law on night sky protection and rational use of energy.

A team of professional and amateur astronomers, engineers, designers, and lawyers are working to implement different actions to create a network of citizens devoted to protect the sky, and also, the environment and life. As part of a long term program of study of light pollution in Malargüe, where the Cosmic Rays Pierre Auger Observatory is installed, several actions, like global campaigns, planetarium shows, videos and contests were performed. These programs have spread to other cities in the country. As a consequence, a National Law of Sky Protection is actually under study. The community of Malargüe is planning to offer this destination as part of a program of astronomical tourism. All the recent initiatives in Argentina on light pollution control and sky protection have two main lines of action: education and communication with the public. 